\title{
Theoretical Study for an Adsorption Refrigerator
}

\author{
Abdulghani Ramadan ${ }^{1^{*}}$, Khairi Muftah ${ }^{2}$, Abdul-Gaffar Omran ${ }^{3}$, \\ and Saif-Eddin Aloud ${ }^{4}$ \\ ${ }^{1^{*}, 2,3,4}$ Faculty of Engineering, Garaboulli, Elmergib University, Libya \\ e-mail: 1amramadan@elmergib.edu.ly, ${ }^{2}$ Kmelgrad@elmergib.edu.ly
}

\begin{abstract}
Adsorption cooling technology is one of the effective means to convert low grade thermal energy in to effective cooling, which improves energy efficiency and lowers environmental pollution. The main objective of this study is to investigate the thermal performance of an adsorption refrigerator theoretically. The working adsorbent/adsorbate pair used is Granular Activated Carbon, GAC/R134a pair. The effect of different design parameters and operating conditions on the system performance is studied and interpreted. Some assumptions and approximations are also considered. A computer program is written using Matlab. Results show that the equilibrium adsorption capacity is highly affected by the driving temperature and equilibrium pressure. Increasing equilibrium pressure leads to a corresponding increase in the equilibrium adsorption capacity whereas it is value is decreased as the driving temperature increases. Moreover, increasing the driving and evaporator temperatures raise the values of the Specific Cooling Effect (SCE) and Coefficient of Performance (COP). The maximum values of SCE and COP are $60 \mathrm{KJ} / \mathrm{kg}$ and 0.4 corresponding to driving and evaporator temperatures of $100{ }^{\circ} \mathrm{C}$ and $20^{\circ} \mathrm{C}$ respectively. However, increasing the condenser temperature leads to a remarked decrease in SCE and COP of the cooling system. SCE and COP values are $32 \mathrm{KJ} / \mathrm{kg}$ and 0.22 at driving and condenser temperatures of $100{ }^{\circ} \mathrm{C}$ and $40^{\circ} \mathrm{C}$ respectively. When comparing the present study results with literature, there is a good agreement in general. It is clear that the adsorption cooling system can be driven effectively by low grade heat sources such as, solar energy, waste heat energy, geothermal energy...etc.
\end{abstract}

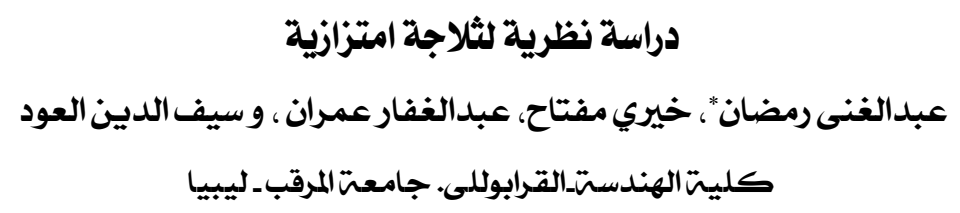

ملحخص: تعتبر تقنيت التبريد الأمتزازي من أهم التقنيات الفعالت التي يتهم عن طريقها تحويل الطاقت الحراريت ذات درجات الحرارة

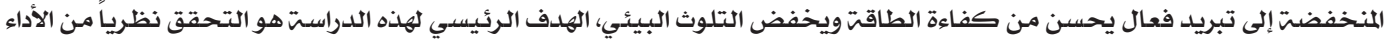

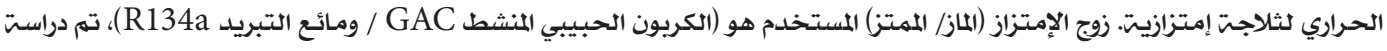

\footnotetext{
* Corresponding author
} 


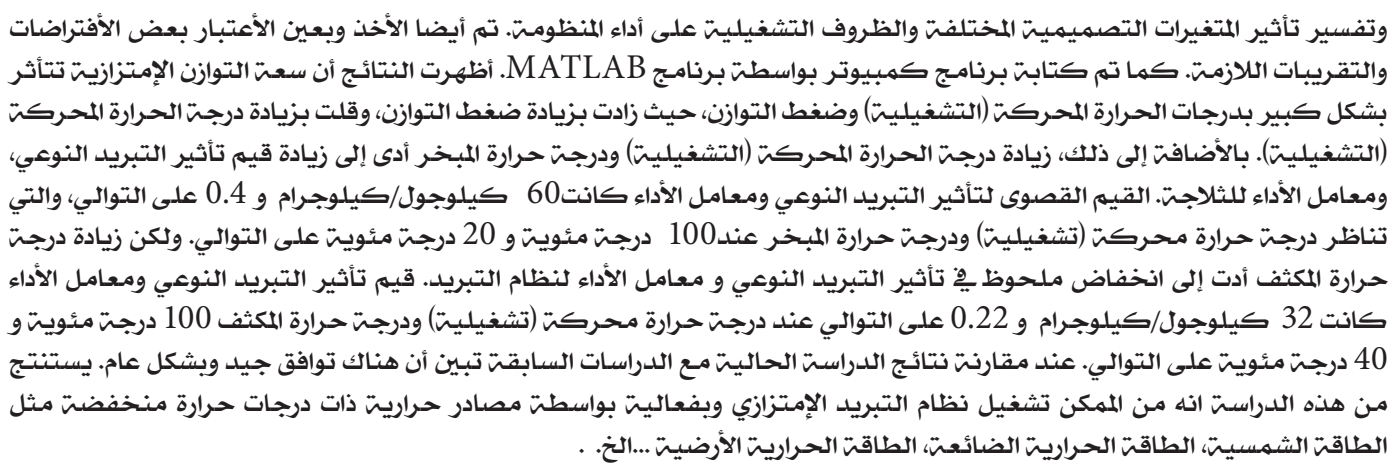

Keywords: Adsorption capacity, cooling, evaporator, condenser, driving temperature, equilibrium pressure.

\section{INTRODUCTION}

Refrigeration may be defined as the process of achieving and maintaining temperature below that of the surroundings, the aim being to cool some product or space to the required temperature. One of the most important applications of refrigeration has been the preservation of perishable food products by storing them at low temperatures. Refrigeration systems are also used extensively for providing thermal comfort to human beings by means of air conditioning. Air Conditioning refers to the treatment of air so as to simultaneously control its temperature, moisture content, cleanliness, odor and circulation, as required by occupants, a process, or products in the space [1].

In recent years, thermal-cooling adsorption systems have received a lot of attention because they are environmentally friendly and can be operated with low temperature sources such as solar energy, lost heat and geothermal energy. Traditional refrigeration and air-conditioning systems have many negative environmental impacts from conventional energy sources and cooling fluids used. These environmental problems are climate change, depletion of the ozone layer and pollution. As well as contribute to the increase in the demand for electricity and the consequent economic problems is to increase the cost of supplying this power. Therefore, solar-powered adsorption cooling systems have the potential to reduce many of these problems. In the adsorbent cooling system, the mechanical compressor known in the conventional electricpowered cooling systems is replaced by a thermal compressor powered by low-temperature energy such as solar energy, geothermal energy or lost energy. On this basis, it does not require electrical energy during operation. Except for the electric power needed to operate the recycling pumps in some cases. Although adsorption cooling systems are not widely distributed in the market, they are considered promising technologies and are of great interest as they do not contain rotary compressors and are sometimes referred to as silent systems.

There are many researches and studies about the subject were conducted in literature, Askalany et al [5] estimated the adsorption characteristics of granular activated carbon (GAC)/R134a pair experimentally. A laboratory scale test rig was designed and built to run the experiments. The adsorption capacity of the GAC was studied at different temperatures $25^{\circ} \mathrm{C}, 35^{\circ} \mathrm{C}, 45^{\circ} \mathrm{C}$ and $65^{\circ} \mathrm{C}$. Pressure and time were recorded during the experiments. The maximum adsorption capacity was found to be $1.68 \mathrm{~kg} \mathrm{R} 134 \mathrm{a} / \mathrm{kg}$ carbon at $25^{\circ} \mathrm{C}$ after 1000 seconds. The activation energy and the exponential constant were estimated to be $9575 \mathrm{~J} / \mathrm{mole}$ and 1.83 respectively.

Askalany et al [8] designed and built an adsorption cooling system employing granular activated carbon $(\mathrm{GAC}) / \mathrm{R} 134 \mathrm{a}$ as adsorbent refrigerant pair. The performance of the system has been determined varying 
driving heat source inlet temperatures and delivered evaporator temperatures. The maximum driving heat source temperature is kept below $100{ }^{\circ} \mathrm{C}$ to utilize solar thermal energy or waste heat sources. The results showed good agreement between the theoretical and experimental data. The maximum theoretical coefficient of performance (COP) is obtained as 0.35 . The experimental specific cooling energy (SCE) is reached up to $70 \mathrm{~kJ} / \mathrm{kg}$ whereas the maximum theoretical SCE of the system is $83 \mathrm{~kJ} / \mathrm{kg}$. The pressurized-bed adsorption cooling system can effectively utilize low grade waste heat of temperature below $100{ }^{\circ} \mathrm{C}$.

Attala and Sadek [9] investigated the adsorption characteristics of granular activated carbon GAC/R-134a pair in the temperature range of $20^{\circ} \mathrm{C}-60^{\circ} \mathrm{C}$ and pressure up to 10 bars. The Dubinin-Astakhov adsorption equilibrium model is fit to experimental data with acceptable error limit. The pressure-temperatureconcentration (P-T-X) diagram of the pair is also presented. The isosteric heat of adsorption of R-134a on activated carbon has been calculated using the Clausius-Clapeyron equation as a function of adsorption capacity. The maximum adsorption capacity was found to be $1.92 \mathrm{~kg} \mathrm{R} 134 \mathrm{a} / \mathrm{kg}$ carbon at $20^{\circ} \mathrm{C}$ after $1200 \mathrm{~s}$. The experimental results also show that the increase of heat transfer area improves the adsorption capacity per kg of adsorber, which leads to the design of a finned tubes heat exchanger adsorption unit.

This paper presents a theoretical study for an adsorption refrigerator. The effect of different design parameters and operating conditions known to affect the thermal performance of the adsorption cooling system under prevailing conditions of Tajoura-Libya has been investigated. The operating Adsorbent/ Adsorbate pair used is (Granular Activated Carbon / R134a). In addition, a comparison between present study results and others from literature was carried out, discussed and interpreted.

\section{ADSORPTION CYCLE DESCRIPTION}

The basic adsorption cycle for cooling consists of four processes represented in Figure 1. A, B is an isosteric heating process. $\mathrm{B}, \mathrm{C}$ is an isobaric heating process. Cooling of the adsorbent provokes a drop of pressure in the collector (process C,D). Meanwhile, the liquid refrigerant is transferred into the evaporator the adsorbent continues to decrease in temperature and pumps the liquid refrigerant, which evaporates and extracts heat from the evaporator (process D-A) generating a cooling effect.

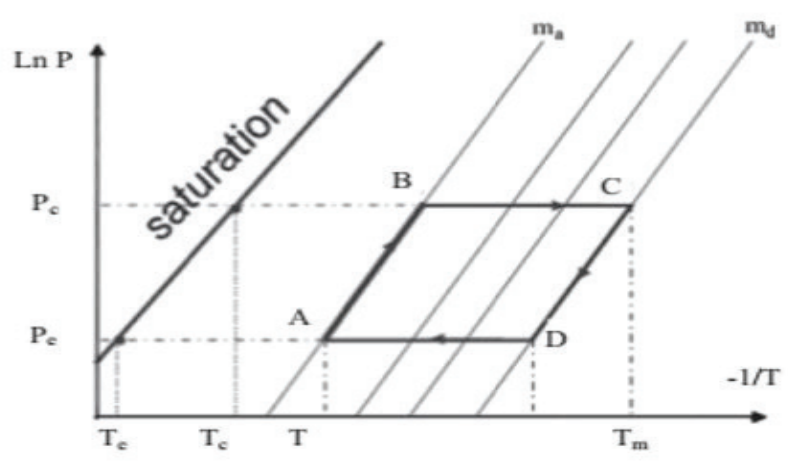

Figure (1-a). Adsorption cooling in Clapeyron diagram [2]. 


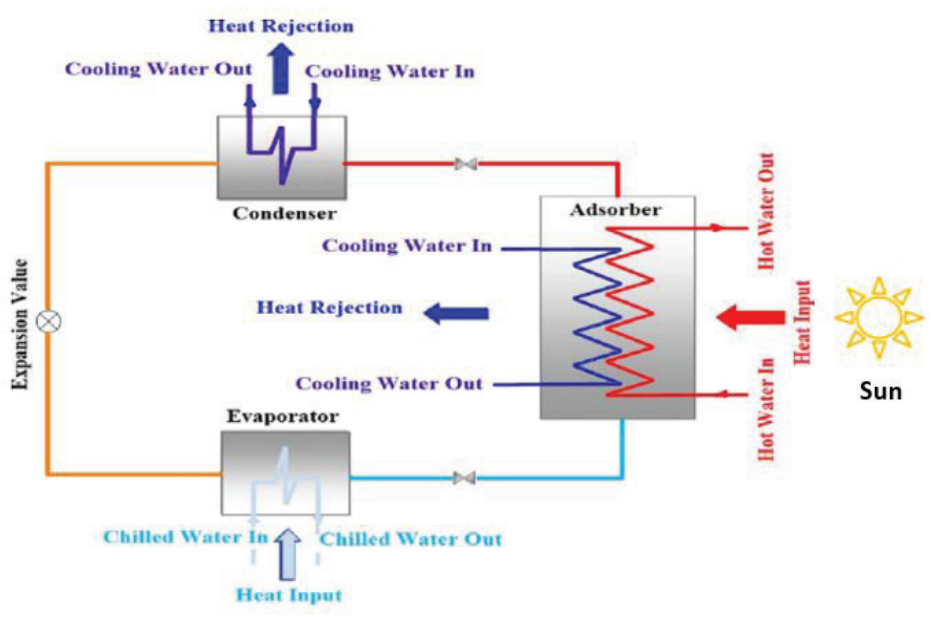

Figure (1-b). Schematic view of a simple adsorption refrigerator system [3].

\section{MATHEMATICAL MODELING}

The lumped model presented everywhere in the literature, [4-8], is applied for this study to investigate the effect of different parameters on the adsorption-desorption phenomena of GAC-R134a pair. This model is mainly based on mass balance and energy balance equations in addition to other related correlations. Herein are the main formulation and the governing equations used. The governing equation for the adsorption pairs is Dubinin-Astakhov (D-A), Equation 1, which is usually used in the estimation of the equilibrium adsorption/desorption quantity in physical adsorption. The Clapeyron diagram will be used here to obtain the adsorption cooling cycle. The main simplifying assumptions are as follows:

- The density of dry adsorbent is constant.

The adsorbent bed is composed of uniform-size particles and the bed porosity is constant.

The heat transfer in the heating or cooling fluids and in the metal tube is one-dimensional.

The temperature and the pressure in the space between the adsorbent and the outer tube are uniform [4].

$$
W=W_{0} \exp \left\{-\left[\left(\frac{R T}{E}\right) \ln \left(\frac{P_{s}}{P}\right)\right]^{n}\right\}
$$

E, $W_{0}$ and $\mathrm{n}$ were determined experimentally as $93.85 \mathrm{~kJ} / \mathrm{kg}, 1.68$ and 1.83 [5].

\subsection{Desorption}

Desorption process is divided into two processes: isosteric heating and isobaric heating. The isosteric heat per kg of adsorbent is determined by equation (2) which is defined as Clausius-Clapeyron [6].

$$
h_{s t}=-R \frac{\partial \ln P}{\partial\left(\frac{1}{T}\right)}
$$

As it was found that a plot of $\frac{h_{s t}-h_{f g}}{E}$ is only a function of temperature [6]. The equation with the correction is written as in equation (3): 


$$
q_{s t}=h_{f g}+E\left\{\left(\ln \left(\frac{W_{0}}{W}\right)\right)^{\frac{1}{n}}+a\left(\frac{T}{T_{c r}}\right)^{b}\right\}
$$

The values of the constants a and $\mathrm{b}$ for $\mathrm{R} 134 \mathrm{a}$ are 1.81 and 6.25 respectively [6]. The critical temperature for R134a is $100.9^{\circ} \mathrm{C}$ so Equation 3 could be in the form of Equation 4.

$$
q_{s t}=h_{f g\left(T_{R 135 a}\right)}+93.85\left\{\left(\ln \left(\frac{1.68}{W}\right)\right)^{0.55}+1.81\left(\frac{T}{373.9}\right)^{6.25}\right\}
$$

The Desorption heat amount of the system per kg of GAC is calculated from equation (5) [7].

$$
q_{d e s}=q_{a c}+q_{r}
$$

Where;

$$
\begin{aligned}
q_{a c} & =\int_{a}^{c} c p_{a c} d T \ldots \ldots \ldots \ldots \ldots \ldots \ldots \ldots \ldots \ldots \ldots \ldots \ldots \ldots \ldots \ldots \ldots \ldots \ldots \ldots \ldots \ldots \ldots \ldots \ldots \\
q_{r} & =W_{0} \int_{a}^{b} c p_{r} d T+\int_{b}^{c} W_{c} p_{r} d T+q_{s t}^{c} d W
\end{aligned}
$$

Dissipated heat by the metal body of the bed during desorption process should be taken in account. It is determined by Equation 8, however; the total heat added to the system through desorption process is calculated by using Equation 9. Equation 10 shows the heat balance of the bed during desorption process.

$$
\begin{aligned}
& q_{m}=m_{m} c p_{m}\left(T_{c o n}-T_{a c}\right) / m_{a c} \\
& Q_{\text {des }}=m_{a c}\left(q_{\text {des }}+q_{m}\right)\left(\frac{1}{d t_{d e s}}\right) \\
& Q_{\text {des }}=m_{f} c p_{w}\left(T_{h w_{\text {in }}}-T_{h w_{\text {out }}}\right) . .
\end{aligned}
$$

\subsection{Adsorption}

The total amount of heat rejected during adsorption process is calculated by using Equation 11 . The heat balance for adsorption process is presented in Equation 12.

$$
Q_{a d s}=m_{a c}\left(q_{a d s}+q_{m}\right)\left(\frac{1}{d t_{a d s}}\right)
$$

Where;

$$
\begin{aligned}
& q_{a d s}=\int_{c}^{a} c p_{c} d T+W_{c} \int_{c}^{d} c p_{r} d T+\int_{d}^{a} W c p_{r} d T+q_{s t} \int_{c}^{a} d W \\
& Q_{a d s}=m_{\text {fads }} c p_{w}\left(T_{a c w_{\text {out }}}-T_{a c w_{\text {in }}}\right)
\end{aligned}
$$

\subsection{Condenser heat balance.}

The heat rejected in the condenser is estimated by Equation 14 and the heat balance for the condenser is presented by Equation 15.

$$
\begin{aligned}
& q_{c o n}=\left(W_{b}-W_{c}\right)\left(h_{\text {fon }}+h_{b}\right)+\int_{b}^{c} W_{c p_{r}} d T \\
& Q_{\text {con }}=\frac{q_{\text {con }}}{d t_{c o n}}=U A_{\text {con }} d T
\end{aligned}
$$




\subsection{Cooling effect}

The cooling effect of the cycle could be determined from Equation 16 and the coefficient of performance for one cycle could be derived from Equation 17.

$$
\begin{aligned}
& S C E=\left(W_{b}-W_{c}\right)\left[h_{f g_{r}}-c p_{r}\left(T_{\text {con }}-\text { Teva }\right)\right] \\
& C O P=\frac{S C E}{q_{\text {des }}}
\end{aligned}
$$

\subsection{Solution Procedure}

The above system of governing equations are mathematically manipulated and solved. For this purpose, a computer program has been written in MATLAB which reads input data and solves the equations to get the output data. Results are stored and graphically represented. The operating conditions of the system are tabulated in Table 1.

Table (1). Operating conditions of the system

\begin{tabular}{ll}
\hline Properties & Value \\
\hline Evaporator pressure (bar) & 3.3 \\
Condenser pressure $($ bar $)$ & 7 \\
Adsorption temperature $\left({ }^{\circ} \mathrm{C}\right)$ & 30 \\
Desorption temperature $\left({ }^{\circ} \mathrm{C}\right)$ & 95 \\
\hline
\end{tabular}

\section{RESULTS AND DISCUSSION}

\subsection{The effect of pressure and driving temperature on the equilibrium Adsorption capacity}

Figure 2 and Figure 3 show the effect equilibrium pressure on the equilibrium adsorption capacity of GAC/R-134a pair at different values of driving temperatures of $\left(20,30,40,50 \& 60{ }^{\circ} \mathrm{C}\right)$. As can be seen from Figure 2, the equilibrium adsorption capacity of temperature $20^{\circ} \mathrm{C}$ is considerably larger than those of other temperatures. Also the maximum adsorption capacity that could be reached is $1.68(\mathrm{~kg} / \mathrm{kg})$ at $20^{\circ} \mathrm{C}$ adsorption temperature. The figure also shows that the adsorption capacity rises rapidly in the first period with the increase of equilibrium pressure and then has a slow progress and the adsorption capacity approaches a limiting value.

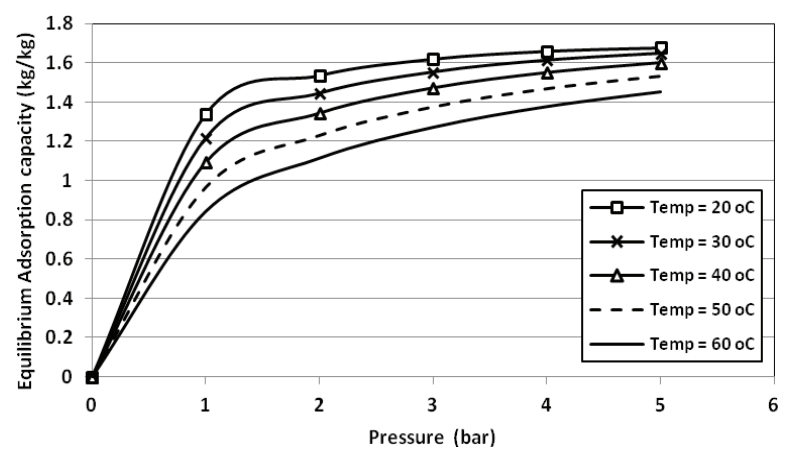

Figure (2). The effect of pressure on the equilibrium adsorption capacity at different values of equilibrium pressures. 
Figure 3 shows the effect of driving temperature on the equilibrium adsorption of GAC/R-134a pair at five different pressures of $(1,2,3,4 \& 5$ bar). It is observed that as the driving temperature increases, the equilibrium adsorption capacity decrease. It varies from its maximum value of $1.68(\mathrm{~kg} / \mathrm{kg})$ at $\left(\mathrm{T}=20^{\circ} \mathrm{C}\right.$ and $\mathrm{P}=5 \mathrm{bar})$ to a minimum value of $1.42(\mathrm{~kg} / \mathrm{kg})$ at $\left(\mathrm{T}=60^{\circ} \mathrm{C}\right.$ and $\left.\mathrm{P}=5 \mathrm{bar}\right)$. As a result, the adsorption capacity reached its maximum value at low temperature and then decreases with the increase of temperature. However, adsorption capacity increases with a corresponding increase in the equilibrium pressure.

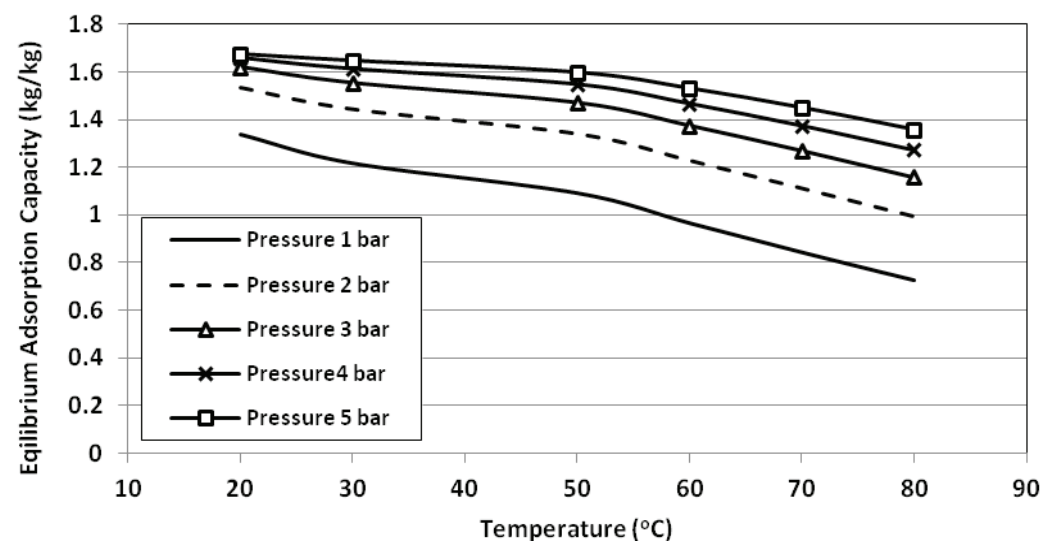

Figure (3). The effect of driving temperature on the equilibrium adsorption capacity at different values of equilibrium pressures.

\subsection{The effect of driving temperature and evaporator temperature on the specific cooling capacity and coefficient of performance}

Figures 4 and 5 show the effect of changing driving source temperature on the SCE and COP respectively at different evaporator temperatures $\left(-5,5,10,15 \& 20^{\circ} \mathrm{C}\right)$ and at constant condenser temperature of 30 ${ }^{\circ} \mathrm{C}$. Results reveal that there is a noticeable increase in the specific cooling capacity and in the coefficient of performance as the driving temperature and evaporator temperature rise to higher values. SCE values varies from $11 \mathrm{~kJ} / \mathrm{kg}$ at driving temperature of $70{ }^{\circ} \mathrm{C}$ to about $42 \mathrm{KJ} / \mathrm{kg}$ at a driving temperature of $100{ }^{\circ} \mathrm{C}$ at a constant evaporator temperature of $5{ }^{\circ} \mathrm{C}$ to a corresponding increase of SCE from $15 \mathrm{~kJ} / \mathrm{kg}$ to $60 \mathrm{~kJ} / \mathrm{kg}$ at driving temperatures of 70 and $100{ }^{\circ} \mathrm{C}$ respectively at a corresponding constant evaporator temperature of $20 \mathrm{oC}$. The same trend is remarked on the effect of increasing driving source temperature and evaporator temperature on COP. Again COP values change from about 0.13 to 0.26 at evaporator temperature of $-5^{\circ} \mathrm{C}$ to about 0.18 to 0.38 at evaporator temperature of $20^{\circ} \mathrm{C}$. As a result, SCE and COP values increase by increasing driving source temperature and evaporator temperature as well.

This is attributed to the fact that increasing the evaporator temperature at a constant condenser temperature leads to a corresponding increase in the initial pressure of the adsorption process which will decrease the period of the isosteric heating time, leading to relatively higher SCE and COP values. 


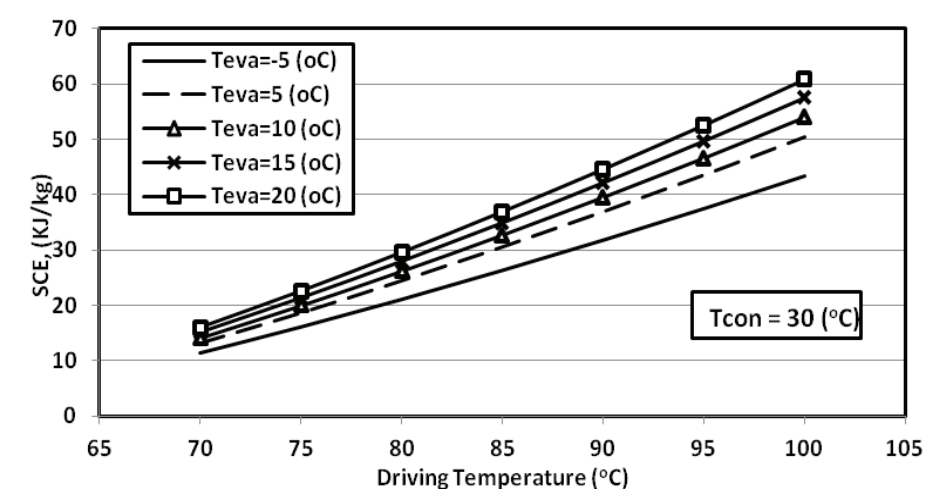

Figure (4). The effect of driving temperature on the specific cooling capacity at different evaporator temperatures.

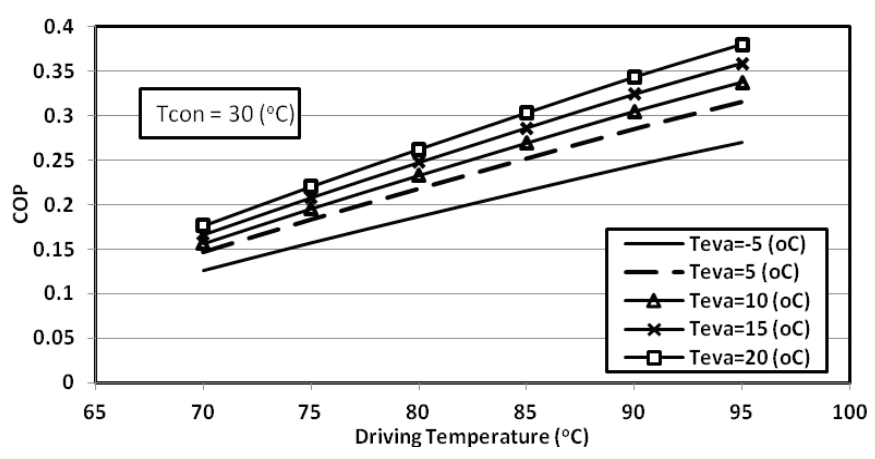

Figure (5): The effect of driving temperature on the coefficient of performance at different evaporator temperatures.

\subsection{The effect of driving temperature and condenser temperature on the specific cooling capacity and coefficient of performance}

Figures 6 and 7 show the effect of changing driving source temperature on the SCE and COP respectively at different condenser temperatures of $\left(30,35 \& 40^{\circ} \mathrm{C}\right)$ and at constant evaporator temperature of $5{ }^{\circ} \mathrm{C}$. Results show that there is a noticeable increase in the specific cooling capacity and in the coefficient of performance as the driving temperature rise to higher values. However, a reverse effect is noticed when increasing the condenser temperature. SCE values varies from $12 \mathrm{~kJ} / \mathrm{kg}$ at driving temperature of $70{ }^{\circ} \mathrm{C}$ to about $50 \mathrm{KJ} / \mathrm{kg}$ at a driving temperature of $100{ }^{\circ} \mathrm{C}$ at a constant condenser temperature of $30^{\circ} \mathrm{C}$ to a corresponding increase of SCE from $2 \mathrm{~kJ} / \mathrm{kg}$ to $32 \mathrm{~kJ} / \mathrm{kg}$ at driving temperatures of 70 and $100^{\circ} \mathrm{C}$ respectively at a corresponding constant condenser temperature of $45 \mathrm{C}$. In contrary, SCE values are decreasing by increasing condenser temperature. Similarly, COP values vary from about 0.15 to 0.33 at condenser temperature of $30 \mathrm{oC}$ to about 0.03 to 0.21 at condenser temperature of $40{ }^{\circ} \mathrm{C}$. Consequently, SCE and COP values increase by increasing driving source temperature and decreasing condenser temperature as well.

This is attributed to the fact that increasing the condenser temperature at a constant evaporator temperature leads to a corresponding increase in the condenser pressure which increases the period of the isosteric heating time, leading to relatively lower SCE and COP values. 


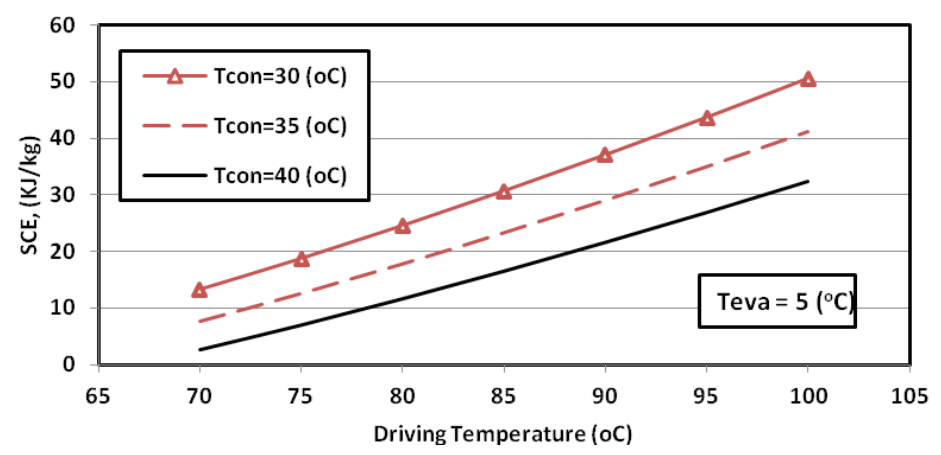

Figure (6). The effect of driving temperature on the specific cooling effect at different condenser temperatures.

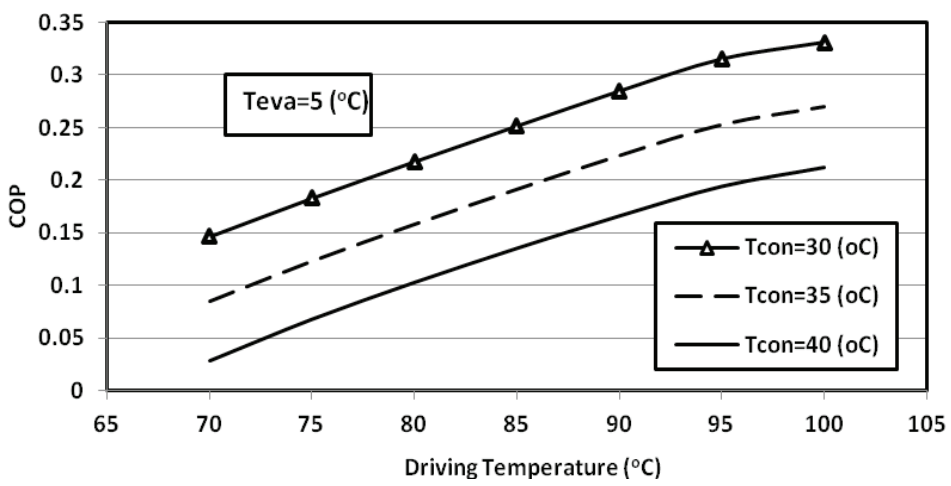

Figure (7). The effect of driving temperature on the coefficient of performance at different condenser temperatures.

\subsection{The effect of evaporator temperature and condenser temperature on the coefficient of performance}

In order to illustrate clearly the effect of condenser temperature and evaporator temperature on the COP of the system, Figures 8 and 9 are designed for this purpose. Figure 8 shows the effect of condenser temperature on the COP of the system at constant driving temperature of $90^{\circ} \mathrm{C}$ and constant evaporator temperature of $5{ }^{\circ} \mathrm{C}$. Increasing the condenser temperature from a value of $15^{\circ} \mathrm{C}$ to $45^{\circ} \mathrm{C}$ lead to a corresponding decrease in $\mathrm{COP}$ from 0.47 to 0.12 . It is clearly shown that increasing in the condenser temperature has a negative effect on the COP of the system.

Figure 9 shows the effect of evaporator temperature on the COP of the system at constant driving temperature of $90^{\circ} \mathrm{C}$ and a constant condenser temperature of $30^{\circ} \mathrm{C}$. Increasing the evaporator temperature from a value of $-5{ }^{\circ} \mathrm{C}$ to $20^{\circ} \mathrm{C}$ lead to a corresponding increase in COP from 0.25 to 0.34 . It is clearly shown that increasing in the evaporator temperature has a positive effect on the COP of the system. 


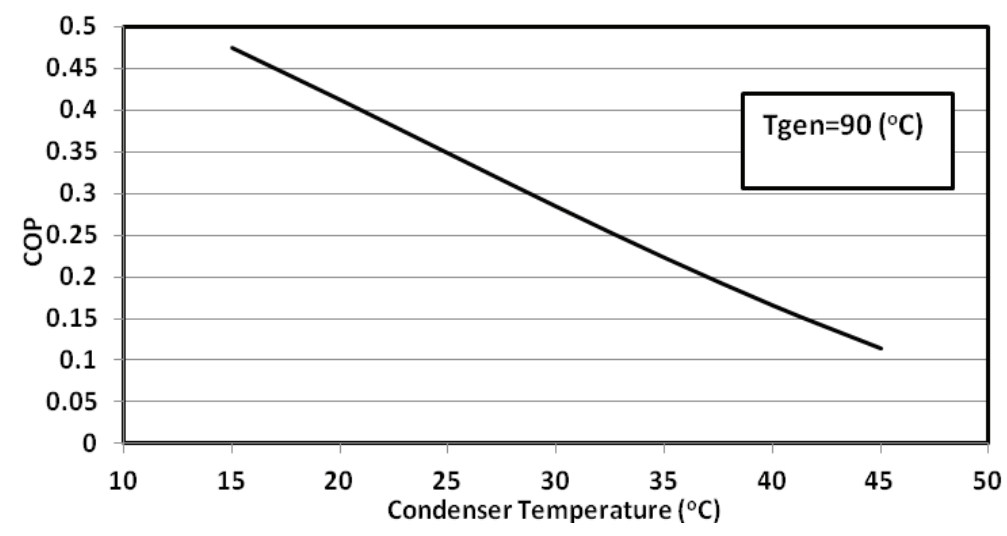

Figure (8). The effect of condenser temperature on the coefficient of performance.

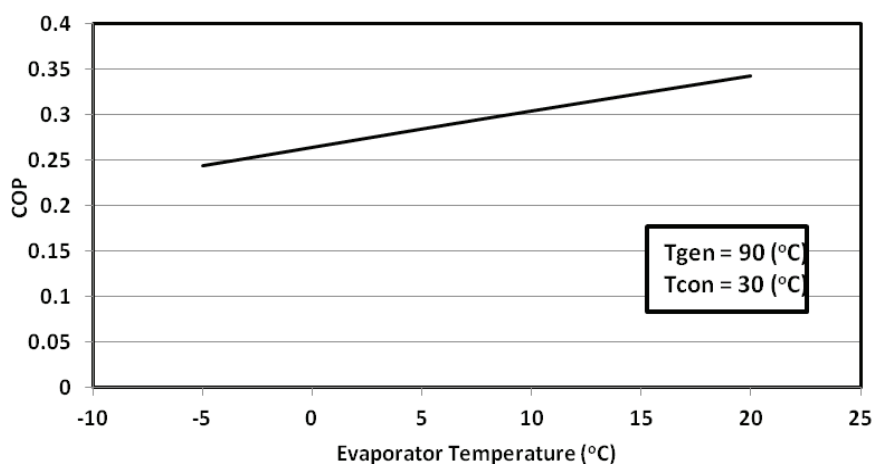

Figure (9). The effect of evaporator temperature on the coefficient of performance.

\subsection{Comparison of Results}

Figure 10 shows a comparison between the present study results and others from literature. The present study results for the equilibrium adsorption capacity are compared with others from literature namely, Askalany et al, Saha et al and Attala \&Sadek [9]. It is clear from the figure that there is a good agreement between the present study results and Saha et al. Whereas, there is a small deviation between the present study results and Attala \& Sadek ranges from ( $+1 \%$ at pressure of 1 bar to $+10 \%$ at pressure of 5 bar) in addition to a corresponding bias of $(-2 \%$ to $-8 \%)$ with Askalany et al. The main reason for this discrepancy is attributed to the difference in Activated carbon properties used for such studies since there are several types in the market.

Figure 11 shows a comparison between the present study results and the results from Askalany et al [5] for specific cooling capacity. The present study results are compared with theoretical and experimental results at constant evaporator temperature of $7{ }^{\circ} \mathrm{C}$ and at constant condenser temperature of $30^{\circ} \mathrm{C}$. As can be seen in the figure, there is a noticeable discrepancy especially with theoretical results of askalany et al. This is may be attributed to the difference in GAC material properties and to the approximations related to the physical and thermodynamics properties of the adsorbate/adsorbent (GAC/R134a) used. For example the assumption of constant properties (specific heat, density ...etc). 


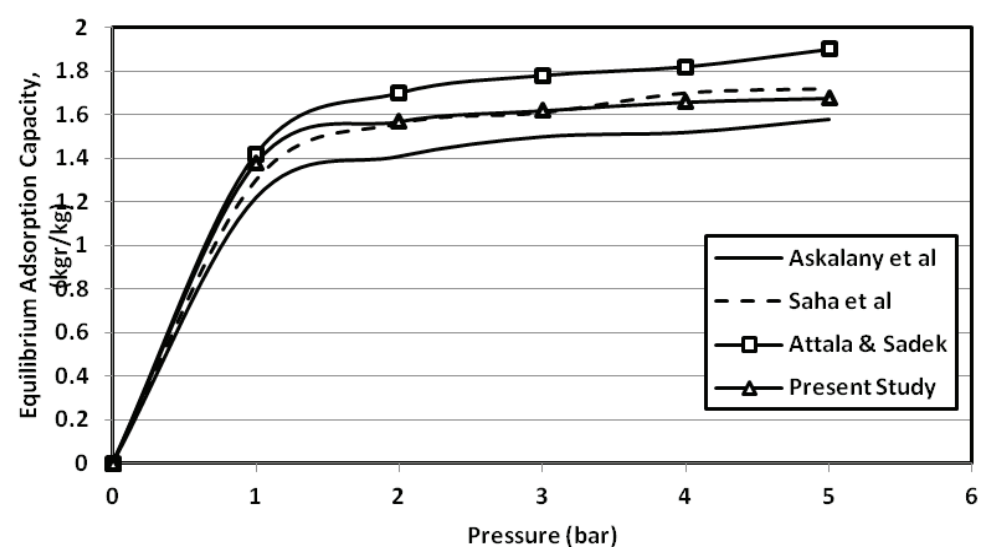

Figure (10). Comparison between the present study results and literature for equilibrium adsorption capacity.

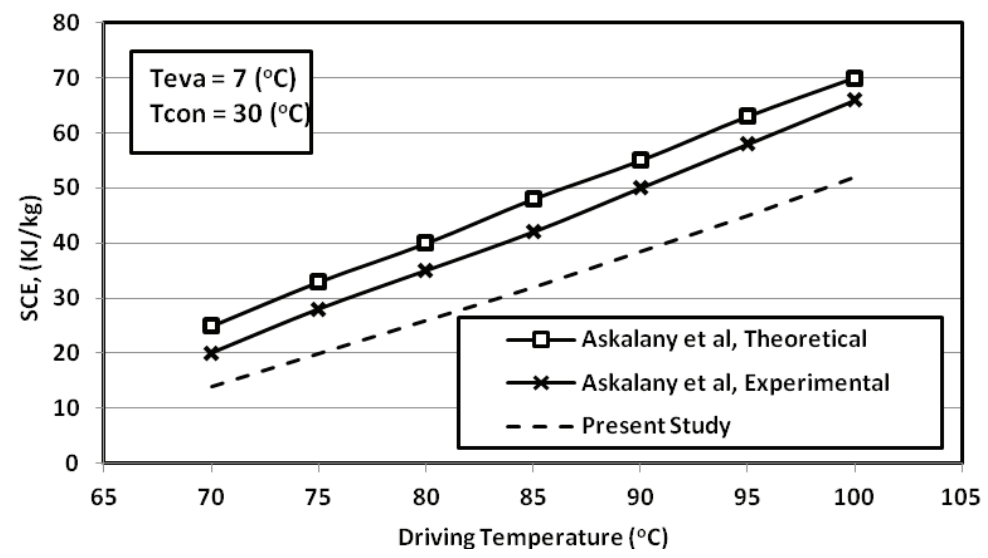

Figure (11). Comparison between the present study results and literature for specific cooling capacity

\section{CONCLUSIONS}

In this research work, an adsorption cooling system is modeled and theoretically investigated. The effect of the main parameters and operating conditions known to affect the system performance are closely studied and analyzed. The main concluding remarks are;

- Equilibrium adsorption capacity is highly affected by the driving temperature and equilibrium pressure. It increases by increasing equilibrium pressure and decreasing by a corresponding increase of the driving temperature.

- Increasing the driving temperature raises the theoretical values of the SCE and COP of the cooling system.

- Increasing the evaporator temperature raises the values SCE and COP.

- Increasing the condenser temperature leads to a remarked decrease in SCE and COP of the cooling system.

- When comparing this study results with literature, there is a good agreement between the present study results and literature.. 
- The adsorption system can be driven effectively by low grade heat sources such as, solar energy, waste heat...etc.

\section{NOMENCLATURE}

\begin{tabular}{llll}
\hline Symbols & & Subscripts & \\
\hline $\mathrm{a}$ & Constant & ac & Activated carbon \\
$\mathrm{b}$ & Constant & ads & Adsorption \\
$\mathrm{Cp}$ & Specific heat, $(\mathrm{kJ} / \mathrm{kg} / \mathrm{k})$ & $\mathrm{Con}$ & Condenser \\
$\mathrm{COP}$ & Coefficient of Performance & $\mathrm{c}$ & Condenser \\
$\mathrm{E}$ & Characteristic energy, $(\mathrm{kJ} / \mathrm{kg})$ & $\mathrm{cr}$ & Critical \\
$\mathrm{h}_{\mathrm{fg}}$ & Latent heat, $(\mathrm{kJ} / \mathrm{kg})$ & $\mathrm{des}$ & Desorption \\
$\mathrm{h}_{\mathrm{st}}$ & Isosteric heat of adsorption, $(\mathrm{kJ} / \mathrm{kg})$ & eva & Evaporator \\
$\mathrm{m}$ & Mass, $(\mathrm{kg})$ & $\mathrm{e}$ & Evaporator \\
$\dot{\mathrm{m}}$ & Mass flow rate, $(\mathrm{kg} / \mathrm{s})$ & $\mathrm{f}$ & fluid \\
$\mathrm{n}$ & Exponential constant & in & Inlet \\
$\mathrm{P}$ & Pressure, $($ bar $)$ & out & Outlet \\
$\mathrm{q}$ & Heat per mass of the adsorbent, $(\mathrm{kJ} / \mathrm{kg})$ & $\mathrm{m}$ & Metal \\
$\mathrm{R}$ & Universal gas constant, $(8.314 \mathrm{~J} / \mathrm{mole} / \mathrm{K})$ & $\mathrm{r}$ & Refrigerant \\
$\mathrm{T}$ & Temperature, $(\mathrm{K})$ & $\mathrm{s}$ & Saturation \\
$\mathrm{Q}$ & Power, $(\mathrm{kW})$ & $\mathrm{st}$ & Isosteric heat \\
$\mathrm{W}$ & Adsorption mass capacity, $(\mathrm{kJ} / \mathrm{kg})$ & & \\
\hline
\end{tabular}

\section{REFERENCES}

[1]. NPTEL Courses, "History of refrigeration", Version 1 ME, IIT Kharagpur, 1999.

[2]. Ahmed A. Askalany, M. Salem, I.M. Ismael, A.H.H. Ali, M.G. Morsy, Bidyut B. Saha," An overview on adsorption pairs for cooling", Renewable and Sustainable Energy Reviews, Vol. 19, pp 565-572, 2013.

[3]. Dalia Attan, M.A. Alghoul, B.B. Saha, J. Assadeq, K. Sopian," The role of activated carbon fiber in adsorption cooling cycles". Renewable and Sustainable Energy Reviews, 15, pp 1708-1721, 2011.

[4]. El-Sharkawy, I.I., Saha, B.B., Koyama, S., Srinivasan, K., "Isosteric heats of adsorption extracted from experiments of ethanol and HFC 134a on carbon based adsorbents", Int. J. Heat Mass. Transfer, Vol. 50, pp 902-907, 2007.

[5]. Askalany, A.A., Salem, M., Ismael, I.M., Ali, A.H.H., Morsy, M.G., "Experimental study on adsorption-desorption characteristics of granular activated Carbon/R134apair", Int. J. Refrigeration, Vol. 35, pp 494-498, 2012.

[6]. Habib, K., Saha, B.B., Chakraborty, A., Koyama, S., Srinivasan, K., "Performance evaluation of combined adsorption refrigeration cycles", Int. J. Refrigeration, Vol. 34, pp 129-137, 2001.

[7]. Loh, W.S., El-Sharkawy, I.I., Ng, K.C., Saha, B.B., "Adsorption cooling cycles for alternative adsorbent/adsorbate pairs working at partial vacuum and pressurized conditions", Appl. Therm. Eng., Vol. 29, pp 793-798, 2009..

[8]. Ahmed A. Askalany, Bidyut B. Saha, Mahmoud S. Ahmed, Ibrahim M. Ismail," Adsorption cooling system employing granular activated carbon-R134a pair for renewable energy applications", International Journal of Refrigeration, Vol.36, pp 1037-1044, 2013.

[9]. M. Attalla, S. Sadek "Experimental Investigation of Granular Activated Carbon/R-134a Pair for Adsorption Cooling System Applications”, Journal of Power and Energy Engineering, Vol. 2, pp 11-20, 2014. 